\title{
RESPONSABILIDAD DE LA EMPRESA ANTE LA PERSONA HUMANA
}

Isabel Parés Gutiérrez

\section{RESUMEN}

LA RESPONSABILIDAD DE LA EMPRESA ANTE LA PERSONA HUMANA IMPLCA fomentarla formación y automealización de sus empleados; al considerarlos individuos con facultades (intelectiva y volitiva), dignos y libres, deben actuar con responsabilidad. La empresa debe guiarse porla Ética, para que el individuo, la empresa misma y la sociedad - pormedio de la educación, para y en el trabajo - atiendan a una necesidad social y contribuyan así al bien común.

\section{ABSTRACT}

The enterprise's responsibility for the human being implies to promote education and self-realization of employees; the enterprise ought to act responsibly considering them individuals with skills (intelligence and will), dignity and freedom. The company must be led through ethics, so the individual, the enterprise itself and the society -through education forand atwork- assist a social necessity and so contribute for the common well-being.

\section{INTRODUCCIÓN}

Hoy vivimos una fuerte crisis de valores. Gran parte de la sociedad, ha perdido la verdadera concepción sobre la persona humana, como un ser con capacidad intelectiva y con voluntad, que actúa con libertad y dada la cual debe ser responsable. Al parecer, la empresa ha olvidado esto, y en ocasiones, utiliza a la persona como un mero productorde capital, capaz de trabajary consumirúnicamente; esta visión da una perspectiva limitada de las personas involucradas en los procesos empresaniales productivos. 
Es de suma importancia la responsabilidad social de la empresa, aspecto que frecuentemente se deja de lado, pero que está vigente; su olvido ha provocado muchas carencias en el actual sistema empresarial. Analizar el tema puede ser el principio de un proceso que haga conscientes a los empresarios de su responsabilidad, tanto con su personal, como para con su empresa y con la sociedad.

Al considerar a la persona humana» debemos tomar en cuenta sus facultades, principalmente inteligencia y voluntad. Bien afirma Yepes que lo propiamente humano es la capacidad de darse a sí mismo fines, y de elegir los medios para llevarlos a cabo». Gracias a ambas facultades, la persona posee intimidad, capacidad de diálogo y libertad, para dary recibir, como notas caractenísticas que conforman su personalidad.

\section{BINOMIO LIBERTAD-RESPONSABILIDAD}

Es la libertad del individuo la que lo hace responsable de sus propios actos al elegir los medios necesarios para alcanzar su fin.

La responsabilidad se deriva de la libertad y se define como ła capacidad que tiene el sujeto de los actos humanos de ser libre para asumir o responderde los actos que realiza y las consecuencias que se denivan de ellos». El ser humano debe ser responsable de sus actos y sus implicaciones; pero para afrontaresta capacidad, es necesario educar en, con y para la responsabilidad.

Si bien la libertad está limitada por la propia naturaleza humana, la responsabilidad no tiene límites, pues de un acto libre se deniva una acción responsable que debe abarcar todas las consecuencias denivadas de dicho acto.

\section{EMPRESA Y RESPONSABILIDAD}

La empresa es un ámbito social y como tal no está aislada; se mueve en consonancia con la sociedad. Tiene como objetivos sociales satisfacerlas necesidades de los consumidores con bienes y/o servicios de calidad; incrementar el bienestar socio-económico de la región 
mediante fuentes de trabajo; contribuiral sostenimiento de los servicios públicos; mejorary conservar el entorno y producir bienes y servicios que no sean nocivos, sino que contribuyan al bienestar social.

De la concepción que se tenga de la empresa, deniva la importancia que se le dé al capital económico y al humano que en ella subyace. Ła empresa no debe considerarse sólo como un factorde incremento económico, sino también, e incluso antes, como auténtica fonjadora de humanidad, como crisol de personalidades maduras y equilibradas. (...) El trabajo sólo perfecciona al hombre en su índole de persona cuando se configura como lo que efectivamente es en su esencia más íntima: como expresión y acabamiento del amorpersonal».

Podemos decirque si la empresa asume el papel de organización educadora, debe considerar los cuatro pilares educativos que dicta la UNESCO: aprender a conocer, aprender a hacer; aprender a vivir juntosy aprender a ser. Al realizarlo, logrará trascender socialmente al serco-responsable del perfeccionamiento humano de sus empleados.

La responsabilidad social puede serconsiderada como la necesidad de lograrun equilibrio entre los intereses públicos y empresariales, tomando en cuenta a la población en general, a quien sirve y con quien la empresa está asociada.

Para tener una idea más clara de la responsabilidad social, debemos considerar sus dos vertientes: la responsabilidad social externa que se refiere a todo lo relacionado con la interacción de la comunidad y de los consumidores, así como de la ecología; y la responsabilidad social intema que señala lo relacionado con las condiciones de trabajo, los grupos minoritarios, la educación y la diversión.

El término responsabilidad social»es un pleonasmo. La verdadera responsabilidad implica necesariamente una vertiente social; esto es, la responsabilidad es una caracteństica del ser humano y éste, en su esencia, posee una dimensión social. Sin embargo, hoy día hemos tenido que usar este término debido a que no existe una sólida concepción del significado de responsabilidad.

Ahora bien, si partimos de la idea de que: «el hombre debe de 
conseguir los fines existenciales que les son propios, y la sociedad es la unión de los hombres para ayudarse mutuamente en la consecución del ser plenamente humano exigido porlos fines existenciales»; es necesario que estas concepciones básicas se unan a la perspectiva de que la empresa tiene en sí tres fines primordiales ${ }^{5}$ : valorañadido, prestar un servicio a la comunidad en la que radica; y sobrevivir dentro de un sistema ateniéndose a las reglas del juego que tal sistema tiene para la supervivencia.

Con esta idea clara, resulta evidente decir que la empresa, al planeary plantearse objetivos, debe considerar sus fines aunados a una concepción válida de persona y de sociedad. Esto porque la empresa tiene su origen, razón y futuro gracias a personas y, además, porque se encuentra en un contexto social y, portanto, debe ajustarse a los principios ordenadores de la sociedad ${ }^{6}$ que parten de una Ética universal: respeto a la dignidad humana, justicia, libertad, subsidianidad, solidaridad y bien común.

Una de las responsabilidades sociales de la empresa consiste en buscar que las personas que en ella laboran, se autorrealicen, produzcan un beneficio y encuentren en ella un medio para alcanzarlo que desean en cuanto a su desamollo personal y profesional.

Las responsabilidades sociales contienen varios aspectos. Una división que puede mostramos una visión integral de los mismos es la siguiente: bienes y servicios, oportunidades de emprender, oportunidades de invertir, creación y difusión de riqueza, rentas de trabajo y de capital, oportunidades de trabajo, paz social y las aportaciones de la empresa al bien común.

Si tomamos el aspecto referente a las oportunidades de trabajo, debemos señalar que implica la formación y el perfeccionamiento del individuo. Resulta evidente que en la empresa, el trabajador pasa gran parte de su tiempo y que en ella aprende diversas cosas, ya sea de modo formal (cursos de capacitación) o de modo informal (actividades cotidianas).

El ser humano necesita trabajar, tanto para satisfacer sus necesi- 
dades básicas como, y sobre todo, para su propio desarrollo. Esto implica una particular atención al tema del respeto a la dignidad humana; «el derecho natural de trabajar se relaciona también con la dignidad de la persona humana (...) que le da a ésta el deber de proveerpor sí misma, cuando ello es posible, a su mantenimiento, y la de cargar, por su propia cuenta e iniciativa, con sus obligaciones familiares». Además de que la dignidad y el desamollo de la personalidad «se adquieren más por el hecho de trabajarque porel hecho de lograr medios para sustentar su vida»\%.

La empresa - una opción para laborar - presenta una puerta abierta a la formación y debe proporcionar medios para que los empleados hagan su trabajo de manera más eficiente y eficaz, más acorde a sus capacidades y gustos. En pocas palabras, la empresa es una institución social que facilita el que una persona trabaje, alcance una profesión o bien se perfeccione.

Dentro del desarmollo del personal, es frecuente enfrentarse con métodos de motivación y la aplicación de distintas técnicas que fomentan un incremento en la producción. Sin embargo, hacerlo sin tomar en cuenta los valores espinituales, tanto de la persona como del trabajo en sí, conduce a no respetar profundamente al ser humano y a que estas técnicas no sean una foma de mejora, ni una manera de encarecer todavía más el actuar de la empresa.

En cuanto al aspecto de la paz social y las aportaciones de las empresas al bien común, debemos considerar la inclusión de políticas y metas de la propia empresa en el ámbito social; es decirque la empresa, y quienes en ella laboran, deben de defendery colaborar con el cumplimiento de las finalidades sociales. Ésta no es una responsabilidad exclusiva de la empresa y de los empresarios, es una obligación de todos y esto incluye a los sindicatos y asociaciones profesionales.

Las cuestiones anteriormente tratadas nos dejan ver cómo los actores personales en su conjunto con el de la empresa, pueden o no legar a participar del bien común y la mejora social. 
En pocas palabras, una empresa responsable es aquella que se preocupa de entregara la sociedad los bienes y servicios de los que ésta carece, intentando una mejora constante, creando y difundiendo riqueza, levando al cabo las inversiones necesarias y adecuadas, buscando alcanzar un valor económico agregado para que haya rentabilidad tanto del trabajo como del capital, atendiendo a las necesidades de la persona humanay su formación, y elaborar una estructura que se fortalezca de tal modo, que no sólo resulten beneficiadas las personas que participan directamente en el actuar de la empresa, sino que también aproveche al país.

\section{EL EMPRESARIO Y SU RESPONSABILIDAD}

La cabeza de la empresa, el empresano, debe ser el primero en preocuparse por el papel que juega su institución dentro de la sociedad, por el papel trascendente que juegan las responsabilidades sociales que le atañen y por transmitir esta conciencia para que todo el personal camine de manera conjunta y armónica.

En cuanto a las responsabilidades del empresario, agente fundamental del desarrollo empresarial podemos considerar cuatro posturas $^{9}$ :

1. Responsabilidad consecuentereferida a la cualidad del hombre de responder ante los propios actos, sin caer en posturas extremistas. Para ello resulta de gran ayuda contemplar el esquema de «Círculos concéntricos» Esta posición delimita y jerarquiza la responsabilidad que el empresanio debe tenerde sus propios actos. Ante las responsabilidades sociales, el empresanio no puede ni debe saltar a otros círculos de responsabilidad, por muy apremiante que parezca su presencia en círculos más amplios, esto basado en el principio de subsidariedad. 


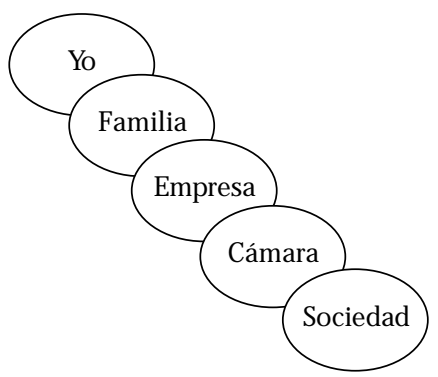

2. Responsabilidad antecedenteque implica responder ante los propios actos (aun cuando no se hayan buscado directamente ciertas consecuencias que se hayan denivado de éstos). En esta categonia, el individuo califica sus actos antes de que se produzcan sus consecuencias. Forja su base en una Ética deontológica ó Ética de principios, pues en ellos encuentra la razón de sus decisiones y portanto de las acciones. Conlleva que el empresanio parta de nomas claras y principios que rijan en la empresa.

3. Responsabilidad congruentedonde las decisiones que el empresanio tome deben tener comelación con sus decisiones pasadas y futuras. En su actuar ha de mostrar congruencia entre lo que piensa, dice y hace; es decir, ser conherente con su propio ser.

4. Responsabilidad trascendenteen la cual desde una visión cristiana, implica que el hombre se responsabiliza de su vida y, así, responde al designio divino. Se refiere a una responsabilidad individual a la vez que genérica por el hecho de ser hombres, de una responsabilidad de oficio, por haberse dedicado a una profesión determinada, a una responsabilidad como miembro de una sociedad, como miembro de una familia, y demás. Requiere de una visión integral de los distintos niveles de responsabilidad. 
Resulta válido pues, insistirque las responsabilidades que acabamos de plantearno son excluyentes sino incluyentes y un buen empresario tiene que responder ante todas ellas; entonces, la repercusión social será la debida.

La empresa no debe preocuparse únicamente por colaborar con el bien común, también debe considerar las demás realidades de tipo social que en ella coinciden. Una de éstas es la inminente necesidad de que la empresa se interese por lograr el perfeccionamiento del personal que en ella labora, tomando en cuenta los derechos y obligaciones de la empresa y los empleados.

Parte de la responsabilidad empresarial ante la persona humana consiste en asumir la obligación de brindar a la persona los medios adecuados para que realice su trabajo, retribuirla con salarios justos y equitativos que vayan de acuerdo a su esfuerzo, respetarla como tal y fomentar su formación y autorrealización. El empresanio debe procurar la creación de fuentes de trabajo para que su empresa mejore y los empleados satisfagan sus necesidades materiales y humanas.

Esta responsabilidad no es única para los países de primermundo, es y debe serparte de todos, pues a pesar de las posibles dificultades que enfrente la empresa y el país mismo, ésta siempre tendrála posibilidad y la obligación de contribuir a la mejora de las personas que con ella interactúan.

\section{LA RESPONSABILIDAD DE LA EMPRESA EN MÉXICO}

En México, debemos emprenderuna campaña que haga conciencia, en primer lugara los empresarios, sobre la responsabilidad social. De tal forma que se valore el papel de la persona en la empresa y la capacidad de perfeccionamiento que tenemos todos los seres humanos. Es frecuente encontramos con empresas que sólo se preocupan porun crecimiento económico, lo cual es un fin lícito, pero no único. Proponemos que dentro de un plan nacional, que valore las repercusiones sociales del ámbito empresanial, se considere el valor de la persona, su formación y automealización dentro de su ámbito de trabajo. 
También seńa importante mencionar, que se debe tomar en cuenta el papel de la mujery sus derechos dentro del ámbito laboral. Desgraciadamente aún siguen existiendo casos en los que se discrimina a las mujeres embarazadas o con hijos; podnía resultar de utilidad, en lugar de discriminarlas, ponerlos medios para facilitarles la combinación de los dos papeles que necesariamente han tenido que asumir, ser madre y ser empleada. Algunos medios que con los que la empresa puede cooperar son: guardeńas y servicios escolares dentro de la empresa, actividades de integración entre los familiares de los empleados y facilidades para la atención de las familias. Esto se basa en la idea, actualmente algo olvidada, de que la familia es la base y núcleo de la sociedad. Desde la familia se pueden generar grandes avances a nivel nacional o se pueden perder los valores fundamentales que conllevan a un decrecimiento social.

En la misma vertiente, debemos considerar a las personas que tengan alguna limitación. En nuestro país, desgraciadamente no contamos con una cultura de ayuda a las personas discapacitadas, olvidando así que quizá, están limitadas en algún área, pero que hay otras en las que pueden realizar un trabajo de calidad. No les debemos negar su capacidad de trabajar, pues como ya lo hemos mencionado es parte del desamollo de la personay es un lugar en el cual se pueden perfeccionary lograr, así, obtener satisfacciones que los impulsen a involucrarse y participar más en la sociedad en lugar de estar marginados.

El caso de los países pobres, la situación de las mujeres y los discapacitados, han sido incluidos porque estos grupos están constituidos por personas con igual dignidad que las demás y por ello hay que respetarlas y ofrecerles una vía de superación y desamollo.

\section{CONCLUSIONES}

El que nuestra sociedad sea consciente de estas responsabilidades, implica educar en la responsabilidad, comenzando desde la familia, la escuela y las empresas. Esto no es tarea fácil. Como un inicio, se 
propone educar en la libertad pues con ella se logra encaminary controlarlos propios actos; la libertad deja que cada individuo marque su meta y la ruta a seguir para alcanzarla. Al provenirlo anterior de un acto libre, el sujeto debe respondery dar, si fuera necesanio, las explicaciones sobre su actuar. Dar cuentas de sus elecciones implica responsabilidad, responder de lo hecho poruno ante alguien, ante la sociedad. Por tanto podemos decir que para educar en la libertad hay que educar en la responsabilidad.

Como miembros de una sociedad, debemos actuar en conjunto para lograr su mejora, por esto cada uno de nosotros tenemos un nivel de responsabilidad social, dependiendo de las circunstancias personales; pero todos, absolutamente todos, tenemos un cierto grado de responsabilidad social que debemos asumir. Hay gente que es más responsable, que tiene más responsabilidades: es el que sabe más y es capaz de intervenin’ ${ }^{\circ}$. Esto es, nadie está excluido, simplemente depende del grado de responsabilidad que tenga de acuerdo con su rol social.

Quienes ostentan la dirección en la empresa han de contar con una escala de valores bien formada, tanto porsu complejidad como por sus prioridades. Lo dice Juan Pablo II: Pertenecera la llamada clase dingente más que un honor es una gravísima responsabilidad que debe ser asumida seniamente $» 1$.

Así concluimos que la responsabilidad social de la empresa requiere guiarse por la Ética, para que la persona, la empresa y la sociedad (por medio de la educación para y en el trabajo), atiendan a las necesidades sociales, y contribuyan al bien común.

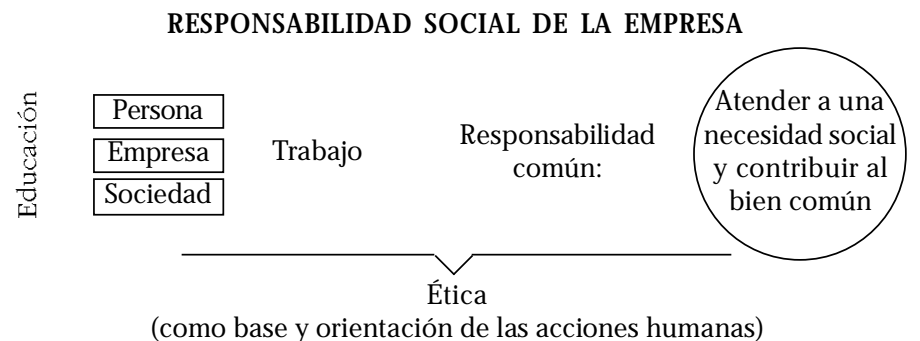




\section{REFERENCIAS BIBLIOGRÁFICAS}

${ }^{1}$ YEPES, R, FundamentosdeAntropología., p.30

${ }^{2}$ GAY BOCHACA, J., Curso deFilosofía fundamental., p.284.

${ }^{3}$ MEIÉ, D., El trauma ético deadelgazarla empresa., p. 47-52.

${ }^{4}$ Íbidem., p.20.

${ }^{5}$ Ídem.

${ }^{6}$ RAIMOND-KEDHILAC, S., Situacionesy gradosdeintervención estatal en la empresa., p.22.

${ }^{7}$ MLLÁN PUELLES., Persona humana yjusticia social., p.122-123.

${ }^{8}$ GALO, M.A., Responsabilidadessocialesdela empresa., p.130.

${ }^{9}$ LANO, C., Desdeel miedo hasta la responsabilidad., p.13.

${ }^{10}$ POLO, L, Ética: hacia una versión moderna delostemasclásicos., p.225. ${ }^{11}$ Íbidem., p.261.

\section{BIBLIOGRAFÍA}

AYLÓN, José Ramón., Entorno al hombre., Rialp., Madrid., 1994., 243 p. DELORS, Jacques., La educación encierra un tesoro., UNESCO., México., 1997., $302 \mathrm{p}$.

GALO, Miguel Ángel., Responsabilidadessocialesdela empresa., Universidad de Navarra., Pamplona., 1980., 217 p.

GAY BOCHACA, Jaime., Curso deFilosofía fundamental., Rialp., Madrid., 1991., 363 p.

GILDER, G., et al., La vertiente humana del trabajo en la empresa., Ed. MiNos., Madrid., 1990., 143 p.

LÓPEZ DE LERGO, Ana Teresa., La empresa yla promoción delosvalores., Colección Humanismo y Empresa., no. 19., México., 1996., 30 p. LANO, Carlos., El empresario antela motivación y la responsabilidad., Mc Graw-Hill., México., 1990., 145 p.

LANO, Carlos., Desdeel miedo hasta la responsabilidad., (P)FNH-131. IPADE., México., 1992.

MELÉ, D., El trauma ético de adelgazar la empresa»en ISTMO., no. 228., México., 1997.

MLÁN PUELLES, Antonio., Persona humana yjusticia social., Rialp., 
México., 1990., 164 p.

POLO, Leonardo., Ética: hacia una versión moderna delostemasclásicos., Publicaciones Cruz O., 1993., 252 p.

RAIMOND-KEDHILAC, Sergio., Situaciones y grados deintervención estatal en la empresa., (P)AEN-109. IPADE., México., 1984.

YEPESS. Ricardo., Fundamentos deAntropología., EUNSA., Pamplona., 1996., $516 \mathrm{p}$. 